\title{
Is believing for a normative reason a composite condition?
}

\section{J. J. Cunningham ${ }^{1}$}

Received: 21 April 2017 / Accepted: 13 November 2017 / Published online: 30 November 2017 (C) The Author(s) 2017

\begin{abstract}
Here is a surprisingly neglected question in contemporary epistemology: what is it for an agent to believe that $\mathrm{p}$ in response to a normative reason for them to believe that $\mathrm{p}$ ? On one style of answer, believing for the normative reason that $\mathrm{q}$ factors into believing that $\mathrm{p}$ in the light of the apparent reason that $\mathrm{q}$, where one can be in that kind of state even if $q$ is false, in conjunction with further independent conditions such as q's being a normative reason to believe that $\mathrm{p}$. The primary objective of this paper is to demonstrate that that style of answer cannot be right, because we must conceive of believing for a normative reason as constitutively involving a kind of rationalityinvolving relation that can be instantiated at all only if there is a known fact on the scene, which the agent treats as a normative reason. A secondary objective, achieved along the way, is to demonstrate that in their Prime Time (for the Basing Relation) Errol Lord and Kurt Sylvan do not succeed in undermining the factoring picture in general, only a simple-minded version of it.
\end{abstract}

Keywords Normative reasons · Reasons for belief · Believing for reasons · Epistemic rationality $\cdot$ The basing relation

Agents can hold beliefs in the light of considerations which appear to them to constitute decisive normative reasons to do so. But agents can also hold beliefs in the light

\footnotetext{
Ancestors of this paper were presented to audiences at the Universities of Warwick, London, Sheffield, and Edinburgh and I would like to thank those present for helpful feedback, objections, and suggestions for improvement. Particular thanks go to Matthew Soteriou, Barnaby Walker, and my pair of anonymous referees at Synthese whose detailed feedback helped improve the paper immeasurably.
}

$凶 \quad$ J. J. Cunningham

joseph.cunningham@jesus.ox.ac.uk

1 Jesus College, University of Oxford, Turl Street, Oxford, Oxfordshire OX1 3DW, UK 
of not merely apparent, but bone fide decisive normative reasons. ${ }^{1}$ Epistemologists working on the nature of the basing relation have paid significant attention to the former phenomenon, ${ }^{2}$ but they have not engaged in much direct discussion of the second. ${ }^{3}$ This is plausibly explained by appeal to the thought that they want to treat the former phenomenon as more fundamental than the second: believing in response to normative reasons, they have taken it, factors into believing in the light of apparent reasons, plus further independent conditions. But are they right to make this factoring move? This question has in turn been surprisingly neglected.

This paper purports to tackle that neglected question. It takes as its starting point a simple-minded version of the factoring move which, following Lord and Sylvan (Forthcoming), I label the Composite View. Lord and Sylvan attempt to refute the Composite View and the first aim of this paper is to demonstrate that they do not succeed in refuting it root-and-branch, for a modified version of it which preserves the core factoring idea survives their attack. The second and main aim is to provide a fresh argument against that core idea. In particular, I argue at length that we need to posit the existence of a kind of believing-for-a-reason relation that can obtain at all only if there is a fact on the scene, known by the agent, which the agent treats as a normative reason to hold the relevant belief, and that on the proper understanding of the sort of factoring picture the Composite View is intended to codify, this serves to undermine that picture.

The issue of whether the factoring picture is correct should be of interest to epistemologists working in the theory of justification, for according to a venerable tradition in epistemology, doxastically justified beliefs are beliefs that are rationally held. ${ }^{4}$ But on the rejection of the factoring picture I aim to promote here, rationally holding a belief can partly consist in the instantiation of a kind of basing relation that requires for its instantiation the presence of a known fact, treated as a normative reason by the agent. If I am right, epistemic rationality can consist in a certain sort of fact-involving status and hence those operating in the venerable tradition are committed to thinking of doxastic justification as being capable of so consisting. This in turn would lay the foundations for a challenge to a Cartesian conception of epistemic rationality according to which it is only ever grounded in factors that are common between agents at the actual world and their envatted duplicates.

I will proceed as follows. Section 1 lays out the distinction between three sorts of cases of rationally held belief, where this is necessary for understanding the dialectic to follow. Section 2 argues that Lord and Sylvan fail to undermine the Composite View in the way advertised. Section 3 provides the fresh argument against the factoring picture. Section 4 takes stock, and then defends that argument against three objections.

\footnotetext{
1 From here-on, I leave it implicit that I am focusing on decisive normative reasons.

2 Although they have not necessarily done so under the description I have used to pick it out.

3 Direct discussion of the second phenomenon is missing, for example, from Korcz (2000), Audi (1993), and Turri (2011).

${ }^{4}$ I take it that this is one way of construing the starting point for an Internalist approach to doxastic justification.
} 


\section{Rationally held belief: three kinds of case}

Some facts constitute normative reasons for us to believe certain propositions. ${ }^{5}$ That the car has four flat tyres is a reason to believe that it is unusable, that the exit-poll predicts a Labour victory in the by-election is a reason to believe that Labour will win, that the guitar is out of tune is a reason to believe that it would sound horrible were it played....and so on.

It is possible for agents to hold beliefs in the light of normative reasons for believing the relevant proposition. Such cases are cases in which the agent believes in a way that manifests a recognition of the fact in question and of its status as a reason to hold the relevant belief. Noticing that the car has four flat tyres, I could come to hold the belief that the car is unusable in a way that manifests my awareness of it's status as a fact which constitutes a reason to believe that the car is unusable, for example. We can record the fact that the agent is in such a situation using a sentence of the following form:

\section{$\left(\neg \psi_{b+}\right) \mathrm{S}$ believes that $\mathrm{p}$ for the good reason that $\mathrm{q}^{6}$}

where ' $q$ ' stands-in for the relevant normative reason for belief and where the 'because' at issue is a rationalising 'because': a kind of 'because' that is applicable only when the agent's belief manifests their treating a consideration as a normative reason to hold that belief. Cases in which the $\left(\neg \psi_{b+}\right)$ condition holds of the agent I will call good $^{+}$ cases.

An agent could, of course, hold a belief in the light of what appears to them to be a normative reason for them to do so, even though they fail to count as being in the $\operatorname{good}^{+}$case. This can happen in either of the following two ways.

First, an agent might believe that $\mathrm{p}$ in a way that manifests their treating $\mathrm{q}$ as a fact which is a reason to believe that $\mathrm{p}, \mathrm{q}$ might be a fact of which the agent is suitably aware, and they might believe that $\mathrm{p}$ in a way that manifests their awareness of the fact that $q$, but fail to believe that $p$ in a way that manifests a recognition of $q$ 's status as a normative reason to believe that $\mathrm{p}$. This happens most straightforwardly when the fact that $q$ isn't really a reason to believe that $\mathrm{p}$ (although it might be a reason to believe something else), as when, for example, the xenophobe believes that the criminal law should treat their neighbour differently to them on the basis of the fact that their neighbour originates from a foreign country. But it might also happen because, although the fact that $\mathrm{q}$ is a reason to believe that $\mathrm{p}$, the agent fails to be appropriately related to the status of the fact that $q$ as a reason to believe that $p$ for their belief that $\mathrm{p}$ to count as manifesting a recognition of that normative status. ${ }^{7} \mathrm{We}$

\footnotetext{
5 For simplicity, my focus here is on what Hieronymi (2005), following Parfit (2001), calls object-given reasons for belief: facts that count in favour of believing because they bear positively on the question of whether the prospectively believed proposition is true.

6 A clarificatory note on the ' $\neg \psi_{b+}$ ' notation. I use ' $\neg \psi$ ' because I want to contrast these non-psychologistic forms of offering rationalising explanations with the psychologistic form I refer to using ' $\psi$ ' later on. I append the sup-script ' $b$ ' to indicate that what we have is an explanation of why the agent believes something. And I attach the ' + ' to contrast the sort of rationalising explanation here with one to be introduced momentarily.

7 Lord and Sylvan's Fortunate Consequent-Affirmer, to be considered in Sect. 2.1, is of this character.
} 
can think of such cases as cases in which the agent believes in a way that is guided by a fact, though not in a way that manifests an attunement to the fact's status as a reason to believe that $p$, if any. When the agent is in this situation, an instance of $\left(\neg \psi_{b+}\right)$ is false of them. But a corresponding instance of the following schema remains true of them:

\section{$\left(\neg \psi_{b}\right) \mathrm{S}$ believes that $\mathrm{p}$ because $\mathrm{q}$}

where q is the fact at issue and, again, the 'because' at issue is a rationalising 'because'. Cases in which the agent holds a belief in a way that manifests an awareness of a fact, but not a recognition of that fact's status as a reason to hold the relevant belief, I will call good $^{-}$cases.

Second, the agent might believe that $\mathrm{p}$ in a way that manifests their treating $\mathrm{q}$ as a fact which is a reason to believe that $p$, even though they fail to manifest an awareness of q's status as a fact at all. This happens most straightforwardly when q is not a fact. But it might also happen when $\mathrm{q}$ is a fact, and the agent fails to believe that $\mathrm{p}$ in a way that manifests an appropriate awareness of q's status as such. ${ }^{8}$ We can think of such cases as cases in which the agent's belief that $\mathrm{p}$ manifests their merely treating $q$ as a fact which is a reason to believe that $p$. When an agent is in this situation, the relevant instance of $\left(\neg \psi_{b+}\right)$ is false of them, as is a corresponding instance of $\left(\neg \psi_{b}\right)$. But an appropriate instance of the following third schema remains true of them:

\section{$\left(\psi_{b}\right) \mathrm{S}$ believes that $\mathrm{p}$ because $\mathrm{S}$ believes that $\mathrm{q}$}

where 'q' stands-in for S's apparent normative reason and, once again, the 'because' at issue is a rationalising 'because'. When the agent believes that $\mathrm{p}$ because they believe that $\mathrm{q}$ without thereby so much as manifesting an awareness of the fact that $\mathrm{q}$, I will say that they are in the bad case.

I have said that in good $^{+}$cases the $\left(\neg \psi_{b+}\right)$ condition holds of the agent. But in fact, the $\left(\neg \psi_{b}\right)$ condition holds of them too: if one believes that the car is unusable for the good reason that the car has four flat tyres, then one also holds that belief because the car has four flat tyres. Believing in the light of a normative reason constitutively involves being guided by the fact which constitutes the relevant normative reason. Likewise, I have said that in the bad case the $\left(\psi_{b}\right)$ condition holds. But in fact, the $\left(\psi_{b}\right)$ condition holds in both of our good cases as well: the agent believes that $\mathrm{q}$ in both good cases, after all, and there seems to be no reason why the agent's belief that $\mathrm{q}$ would fail to count as doing its rationalising work in either of the sorts of good case at issue. So whether the agent believes that $\mathrm{p}$ in the light of the good reason that $\mathrm{q}$, or they believe that $\mathrm{p}$ in the light of the fact that $\mathrm{q}$ which they take to be such a reason, also: they believe that $\mathrm{p}$ because they believe that $\mathrm{q}$. Putting all this together gives us the following picture. The $\left(\psi_{b}\right)$ condition is our most generic condition, holding as it does across good cases and bad. In the good $^{-}$case, as well as the $\left(\psi_{b}\right)$ condition holding: also, the $\left(\neg \psi_{b}\right)$ condition holds. In the good ${ }^{+}$case, as well as the $\left(\psi_{b}\right)$ and

\footnotetext{
8 The sort of Gettier Cases relied on by Hornsby (2008) and Hyman (1999), to be discussed in Sect. 3.2, are instances of this.
} 
( $\left.\neg \psi_{b}\right)$ conditions holding: the $\left(\neg \psi_{b+}\right)$ condition holds. In the bad case, all that holds is the $\left(\psi_{b}\right)$ condition. ${ }^{9}$

\section{Lord and Sylvan's argument against the composite view}

Let us now focus our attention on good ${ }^{+}$cases, and ask: what is it to hold a belief in the light of a normative reason for one to do so? Perhaps the simplest suggestion is that it is for one to believe in the light of an apparent normative reason for one to do so but where, in addition, the apparent reason is genuine. The point of the phrase 'in addition' is to signal that the two factors in terms of which we are to account for the $\operatorname{good}^{+}$case are metaphysically separable: one could believe that $\mathrm{p}$ in the light of an apparent normative reason $\mathrm{q}$, even if $\mathrm{q}$ is not a normative reason for one to believe that $\mathrm{p}$, and vice-versa.

This simple-minded view is what Lord and Sylvan call the Composite View. Let us codify it:

Composite View Necessarily, $S$ believes that $p$ for the good reason that $q$ iff (i) $S$ believes that $\mathrm{p}$ because $\mathrm{S}$ believes that $\mathrm{q}$ and (ii) $\mathrm{q}$ is a normative reason for $\mathrm{S}$ to believe that $\mathrm{p}$.

The remainder of this section considers Lord and Sylvan's argument against the Composite View. Section 2.1 presents the argument. Section 2.2 argues that it is possible to preserve the core motivation for the Composite View whilst rejecting the first premiss of the argument.

\subsection{The argument}

The argument against the Composite View focuses on the possibility of a certain class of cases in which the connection between the agent's apparent normative reason and the normative reason itself is deviant in a certain respect. Since the Composite View is committed to saying, of such cases, that they are good ${ }^{+}$cases, the Composite View is false, so the argument goes.

Let us call the class of cases which are supposed to cause a problem for the Composite View $D$-cases. Thus, the argument can be presented in this way:

(P1) If the Composite View is true, then D-cases are good ${ }^{+}$cases.

(P2) D-cases are not good ${ }^{+}$cases.

(C) The Composite View is false.

What are D-cases? Here is the case Lord and Sylvan present:

\footnotetext{
9 It is now common to distinguish normative reasons from motivating reasons. The latter are the reasons for which the agents act and hold attitudes conceived as things that could be present and counting as reasons even in the bad case. I do not think there are such things as motivating reasons: when the agent is in the bad case, they are not acting or holding an attitude for a reason. Rather, they are doing so because some consideration appears to them to be a normative reason (compare Alvarez (2010)). I have therefore set things up in this section without recourse to the notion of a motivating reason. I do not think anything hangs on this.
} 
Fortunate Consequent-Affirmer. Sam wonders whether Terry took the bus to work. He knows that Terry's car is in the driveway. This is, in fact, a sufficient abductive reason to think that Terry took the bus. Sam also believes that if Terry took the bus, then Terry's car is in the driveway. But he comes to believe that Terry took the bus by inferring that he took the bus from his own belief that Terry's car is in the driveway and his belief that if Terry took the bus, then Terry's car is in the driveway by following an invalid deductive rule: from $<$ if $A$ then $B>$, and $<B>$, infer $<A>$. Sam hereby manifests a general consequent-affirming incompetence. (Lord and Sylvan, Forthcoming: p. 11)

In this case, the agent rationally believes that $\mathrm{p}$ (that Terry took the bus) because they believe that q (that Terry's car is in the driveway), so that they satisfy the ( $\left.\psi_{b}\right)$ condition. But their belief that $\mathrm{p}$ is mediated by the operation of some disposition they have which, in being a disposition to follow an invalid rule of inference, is defective. Cases with this structure are D-Cases.

I am happy to accept (P2): because Sam's belief manifests a disposition to reason in-line with an invalid rule of inference, Sam cannot be counted as displaying the sort of sensitivity or attunement to the normative status of the fact in response to which he holds his belief that's required for being in the $\operatorname{good}^{+}$case. Let us instead focus on how the proponent of the Composite View might respond to (P1).

\section{2 (P1) considered}

To check whether (P1) is true, let us ask: is it plausible that there is some construal of Fortunate Consequent-Affirmer on which Sam's apparent reason matches a genuine normative reason? Such a description is not difficult to find: we can identify the apparent reason in the light of which Sam believes that Terry took the bus with the fact that Terry's car is in the driveway, where Sam's belief in the conditional if Terry took the bus then Terry's car is in the driveway is not part of Sam's apparent reason for belief, but is rather a background belief Sam has which functions merely to enable Sam's belief about the whereabouts of Terry's car to constitute his apparent reason. Moreover, that Terry's car is in the driveway is plausibly a normative reason for Sam to believe that Terry took the bus, by dint of the abductive connection between the two.

(P1), then, is true. Nevertheless, there is a way for the proponent of the Composite View to successfully reply to the argument which focuses on (P1). What they can say is simply this: all that the possibility of D-cases shows is that there is an additional component which needs to be added to the analysis of the good ${ }^{+}$case, namely: if the agent's belief manifests a disposition to reason in accordance with a principle of reasoning at all, the principle of reasoning in question is correct. If we add this third condition to the two conditions already cited we get the following:

Composite View* Necessarily, $\mathrm{S}$ believes that $\mathrm{p}$ for the good reason that $\mathrm{q}$ iff (i) $\mathrm{S}$ believes that $\mathrm{p}$ because $\mathrm{S}$ believes that q; (ii) $\mathrm{q}$ is a normative reason for $\mathrm{S}$ to believe that $\mathrm{p}$; (iii) if $\mathrm{S}$ believes that $\mathrm{p}$ in a way that manifests 
a disposition to reason in accordance with a principle of reasoning at all, then the relevant principle of reasoning is correct.

(P1) is false of the Composite View*: agents in D-cases fail to satisfy condition (iii). But there is no reason why the proponent of the Composite View shouldn't go ahead and endorse the Composite View* instead of the original version of their theory. The latter is identical in all philosophically significant respects to the former, it seems to me, and I don't think Lord and Sylvan themselves say anything which might put pressure on the proponent of the Composite View not to simply go ahead and make the envisaged modification.

Let me elaborate on this by sketching an account, to be developed later on, of what motivates the Composite View in the first place. It seems to me that what motivates the Composite View is the thought that the $\left(\psi_{b}\right)$ condition is a condition which always obtains without it being constituted by some further condition the obtaining of which guarantees that the agent is either in the good ${ }^{+}$case or even the $\operatorname{good}^{-}$case. What the proponent of the Composite View wishes to rule out, in other words, is that there could be a state of holding a belief in the light of an apparent normative reason which is, to some degree, essentially successful in nature: a kind of state which constitutes holding a belief in the light of an apparent normative reason but which is also a kind of state that one could be in only if either one is guided by a fact, so that the $\left(\neg \psi_{b}\right)$ condition holds of one, or (even better) one believes for a normative reason, so that the $\left(\neg \psi_{b+}\right)$ condition holds of one.

This conception of the $\left(\psi_{b}\right)$ condition is in turn one which constrains the account the proponent of the Composite View gives of the $\left(\neg \psi_{b+}\right)$ condition: it requires it to be an account according to which the $\left(\neg \psi_{b+}\right)$ condition factors into the $\left(\psi_{b}\right)$ condition, plus the extra conditions distinctive to the good $^{+}$case, where those conditions are extra in the sense that their obtaining is not necessitated by the obtaining of what grounds agent's satisfaction of the $\left(\psi_{b}\right)$ condition. Likewise, when it comes to giving an account of the $\left(\neg \psi_{b}\right)$ condition, a question we have not yet considered, the conception of the $\left(\psi_{b}\right)$ condition which motivates the Composite View will similarly constrain the style of account which can be offered: the $\left(\neg \psi_{b}\right)$ condition will also have to be thought of as factoring into the $\left(\psi_{b}\right)$ condition, plus extra factors distinctive to the good ${ }^{-}$case.

What matters to the proponent of the Composite View, then, is a certain kind of independence of condition (i) from those other conditions of the account, including (ii), (iii), and any further conditions there might be, which characterise the good ${ }^{+}$ case, so that the sort of factoring account of the $\left(\neg \psi_{b+}\right)$ condition advertised is the one we will have to opt for. Since the Composite View* meets this criterion, it offers everything the proponent of the Composite View wants from their account of the $\left(\neg \psi_{b+}\right)$ condition.

\section{The composite view rejected root-and-branch}

So far, I have defended the claim that the proponent of the Composite View of the good $^{+}$case is able to side-step Lord and Sylvan's attack by modifying their theory in a way that preserves its motivation. But I agree with Lord and Sylvan that we should reject the Composite View, it's just that I think we need to adopt a different 
argument if we're to ensure that the view is refuted root-and-branch, and this is what I intend to supply in this section. Section 3.1 unpacks what it is to reject the very idea that motivates the Composite View, and how I am going to go about doing so. Section 3.2 presents a kind of case already familiar in the literature which I argue cannot, by itself, force a rejection of the idea which motivates the Composite View. Section 3.3 presents a fresh case which I argue is a bad case of rationally believing. Finally, Sect. 3.4 argues that the fresh case can only be handled by rejecting the idea which motivates the Composite View in the way advertised.

\subsection{The structure of the $\left(\psi_{b}\right)$ condition}

It will be recalled that the core motivating idea of the Composite View is the thought that the $\left(\psi_{b}\right)$ condition cannot be constituted by some further condition which suffices for the agent to be in either kind of good case of rationally believing. With this idea in the background, the proponent of the Composite View will in turn offer, and indeed will have to offer, an account of the good ${ }^{+}$case according to which it factors into the obtaining of the $\left(\psi_{b}\right)$ condition plus the further conditions which are necessary for being in the good $^{+}$case, such as conditions (ii)-(iii) of the Composite View*, and will have to offer a structurally analogous account of the $\operatorname{good}^{-}$case.

What exactly is it to take the $\left(\psi_{b}\right)$ condition as a condition which cannot be constituted by a success condition? To answer this question, we need to pay closer attention to the metaphysical structure of the $\left(\psi_{b}\right)$ condition. When the agent believes that $\mathrm{p}$ because they believe that q, we can think of this as a certain kind of (synchronic) relation that holds between their pair of beliefs: a relation the instantiation of which ensures, inter alia, that the belief that q sustains the agent's belief that $\mathrm{p}$ in a way that underpins the truth of the rationalising explanation that can be provided using a corresponding $\left(\psi_{b}\right)$ statement. I will call this relation the rational-motivation relation.

As I understand it, the core idea which motivates the Composite View is that there is only one kind of rational-motivation relation and it is the kind which can obtain whether the agent is in either kind of good case or the bad case: its obtaining only requires that q appears to the agent to be a normative reason to believe that $\mathrm{p}$, not that it be the genuine article. Suitably unpacked, the thought that the $\left(\psi_{b}\right)$ condition cannot be constituted by some further condition which requires the agent to be in one of the good cases just is a commitment to this monistic conception of the rational-motivation relation.

With this monistic conception of the rational-motivation relation in tow, the proponent of the Composite View will then have to account for the good ${ }^{+}$case by saying that it involves the obtaining of one of these neutral rational-motivation relations binding the relevant pair of beliefs, but where, in addition, the factors distinctive to the good $^{+}$ case, such as (ii)-(iii), also obtain. Likewise, they will have to say that the $\operatorname{good}^{-}$case consists in one of those neutral rational-motivation relations binding the relevant pair of beliefs, but where, in addition, the factors distinctive to the good $^{-}$case also obtain. With respect to both kinds of good case, the relevant additional factors are not required to obtain by the nature of the very motivational structure within which the agent's pair of beliefs are located. 
To reject the core motivation for the Composite View is precisely to deny that the rational-motivation relation comes in only this neutral form. In particular, it is to say that in addition to the kind of neutral rational-motivation relation which binds the agent's pair of beliefs just in case the $\left(\psi_{b}\right)$ condition holds, we should also accept the existence of a distinct kind of rational-motivation relation which can bind a pair of beliefs the agent has only if they satisfy either the $\left(\neg \psi_{b+}\right)$ condition or, alternatively, just the $\left(\neg \psi_{b}\right)$ condition.

On the first option, there is a kind of rational-motivation relation the obtaining of which guarantees that the agent believes in the light of a normative reason: they are in the $\operatorname{good}^{+}$case. If we went for this option, we would identify satisfying the $\left(\neg \psi_{b+}\right)$ condition with holding a pair of beliefs bound together by this essentially successful rational-motivation relation, and we would say that the agent's satisfaction of the $\left(\psi_{b}\right)$ condition in the good ${ }^{+}$case is constituted by their satisfaction of the $\left(\neg \psi_{b+}\right)$ condition, so conceived. On the second option, by contrast, there is a kind of rational-motivation relation the obtaining of which guarantees only that the agent is guided by a fact: that the $\left(\neg \psi_{b}\right)$ condition holds. On this second option, we would then identify satisfying the $\left(\neg \psi_{b}\right)$ condition with holding a pair of beliefs bound together by this more minimally successful rational-motivation relation, and we would say that the agent's satisfaction of the $\left(\psi_{b}\right)$ condition in both good ${ }^{+}$and good ${ }^{-}$cases is constituted by their satisfaction of the $\left(\neg \psi_{b}\right)$ condition, so conceived.

These are our options when it comes to rejecting the idea which motivates the Composite View. In what follows, I am going to present an argument for the second option: I will argue for a conception of the $\left(\neg \psi_{b}\right)$ condition according to which the very kind of rationality-implicating relation that binds one's belief that $\mathrm{p}$ with one's belief that q requires one to be guided by a fact. This might, however, seem dialectically odd: I started with a focus on the $\left(\neg \psi_{b+}\right)$ condition, after all, and I have been focusing so far on a debate between Lord and Sylvan and the Composite View, which is a view about how to conceive that condition, not the $\left(\neg \psi_{b}\right)$ condition. In turning my attention to the $\left(\neg \psi_{b}\right)$ condition, how is what I have to say going to be relevant to the issue I started out with?

If I am successful in proving that the $\left(\neg \psi_{b}\right)$ condition constitutively involves the obtaining of a kind of rational-motivation relation special to being guided by a fact, this bears on the question of how to understand the $\left(\neg \psi_{b+}\right)$ condition by providing us with a partial account of what is going on when the $\left(\neg \psi_{b+}\right)$ condition holds, for that condition constitutively involves the agent being guided by a fact. It will not provide us with a full account of the $\left(\neg \psi_{b+}\right)$ condition of course, since being guided by a fact does not suffice for believing for a normative reason. One simple suggestion is that we complete the account of the $\left(\neg \psi_{b+}\right)$ condition by identifying it with believing guided by a fact, plus the satisfaction of condition (iii) of the Composite View*. This would perhaps be worth thinking of as a picture of the $\operatorname{good}^{+}$case according to which it factors into what's common between $\operatorname{good}^{+}$cases and $\operatorname{good}^{-}$cases, plus a condition distinctive to the former. But even so, the weak factoring picture currently at issue should be carefully distinguished from the strong factoring picture which motivates the Composite View, according to which the most basic factor, to which we need to add a set of extra conditions, is a motivational structure common to the good cases and the bad case. I leave it an open question, to be addressed in future 
work, whether the sort of weak factoring picture of the good ${ }^{+}$case just advertised is correct.

Moreover, if I am successful in proving that the $\left(\neg \psi_{b}\right)$ condition constitutively involves the obtaining of a kind of rational-motivation relation special to being guided by a fact, this bears on the debate about the good ${ }^{+}$case between Lord and Sylvan and the proponent of the Composite View in the following two ways. First, and as we have seen, it serves to render the Composite View unmotivated in the first place. But second, the kind of case I present in Sect. 3.3, which I rely on to support my conception of the $\left(\neg \psi_{b}\right)$ condition, in fact serves as a counterexample to the best version of the Composite View anyway, as I will detail at the end of Sect. 3.4. So the upshot will not just be that the Composite View is unmotivated, but that we have a fresh counterexample to its best version.

\subsection{The knowledge connection}

Let us now turn our attention to the task of refuting the core idea that motivates the Composite View in the way advertised. What I want to locate is a case which can be handled only by appeal to the thought that being guided by a fact involves a rationalmotivation relation which can be instantiated at all only if one is guided by a fact.

One kind of case which springs to mind is already familiar in the literature: it is the kind of case presented by Hornsby (2007a, b, 2008) and Hyman (1999), intended by them to support the claim that acting or holding an attitude guided by the fact that $q$ requires knowing that $\mathrm{q}$. Here is a variant of the basic sort of case:

New Film. Jenny decides to go to see the latest Coen Brothers film at her local cinema this evening. She googles the screening times on her laptop, and reads on the cinema's website that the film is being shown at 19:45 and indeed, it is being shown at that time. Thus, Jenny comes to have a justified, true belief that the film is being shown at 19:45. However, unbeknownst to her, the cinema's website has been hacked by pranksters who have assigned to each film a set of prima facie plausible screening times picked at random, leaving everything else about the website the same. It just so happens that the 19:45 showing they assign to the Coen Brothers film is in fact when a showing of that film will occur. Thus, Jenny doesn't know that the film is being shown at 19:45. Moreover, on the basis of her belief that the film is being shown at 19:45, she comes to hold a further belief: that it will end around 22:00.

Does Jenny believe that the film will end around 22:00 guided by the fact that the film will start at 19:45? Hornsby and Hyman say 'no'. Moreover, they argue that the best explanation of why she fails to count as being guided by a fact in holding her belief is that she fails to know that the film starts at 19:45. Thus, they conclude, knowing that $\mathrm{q}$ is necessary for one to believe (and indeed act or hold some other attitude) because q. I follow them in finding all this plausible and will not question it here. ${ }^{10}$ Thus, from

\footnotetext{
10 See Cunningham (Unpublished Manuscript) for a defence of the epistemic condition and the Hornsby/Hyman argument for it.
} 
hereon, we will be taking it that being guided by the fact that q requires nothing short of knowing that $\mathrm{q}$.

The question we need to ask is: does acknowledging this epistemic thesis require us to reject the sort of monistic picture of the rational-motivation relation which motivates the Composite View? I don't think so. To see why not, consider the following account of being guided by a fact that could be offered by the proponent of the monistic picture:

Composite-Guidance $_{K}$ Necessarily, $S$ believes that $\mathrm{p}$ because q iff (i) $\mathrm{S}$ believes that $\mathrm{p}$ because $\mathrm{S}$ believes that q; (ii) $\mathrm{S}$ knows that $\mathrm{q}$.

Composite-Guidance $_{K}$ seems to me to be entirely consistent with cleaving to the core motivation for the Composite View. Someone who wishes to countenance only the neutral kind of rational-motivation relation can perfectly well accept that knowing that $\mathrm{q}$ is a condition required for the $\left(\neg \psi_{b}\right)$ condition, they will just have to regard it as an extra factor that needs to be added to condition (i) in order to yield an account of the $\left(\neg \psi_{b}\right)$ condition. We will have to look elsewhere for a case that gives us what we want.

\subsection{A case of rational incapacitation}

I now want to present such a case. I'll present a straightforward good ${ }^{+}$case of rationally held belief first. I'll then vary the case and argue at length that the details of the variation ensure that the agent no longer counts as believing guided by a fact. Section 3.4 will then argue that we can explain why this is so only by rejecting the monistic conception of the rational-motivation relation.

Here's the straightforward good ${ }^{+}$case I want to start with:

By-Election Believer I. A by-election has taken place in Rhonda's constituency. The votes have not yet been counted, but the exit-poll, which is highly reliable, has been released and it predicts a Labour victory. She is asked by a friend which party she believes will win. Having read that the exit-poll predicts a Labour victory in the also highly reliable local news, thereby coming to know that fact, she answers that Labour will win.

Rhonda believes that Labour will win the by-election because she believes that the exit-poll predicts so. That the exit-poll predicts so is indeed a reason for Rhonda to hold that belief and we can take it that she isn't relying on any incorrect principle of reasoning in holding her belief. And finally, she knows that the exit-poll predicts a Labour victory. Thus, she believes that Labour will win for the good reason that the exit-poll predicts so: she is in the good $^{+}$case. She therefore also believes that Labour will win guided by the fact that the exit-poll predicts so.

But now let us vary the case in the following manner:

By-Election Believer II. Rhonda continues to believe that Labour will win because she believes that the exit-poll predicts a Labour victory. However, unbeknownst to her, Rhonda underwent a piece of brain surgery whilst she slept yesterday evening which has had the following effect: whenever she engages in an episode of conscious reasoning directed towards answering the question: 
Who will win the by-election?, this triggers an apparent memory of having been told that the exit-poll predicts a Labour victory by her brother and causes her to forget reading it in the local news. Although the new memory is not misleading: the exit-poll really does make that prediction, it is unreliable: even if the exit-poll were to have made a different prediction, the apparent memory would still be triggered were she to engage in that deliberation. Still, having already settled the matter of who will win, Rhonda never raises the question again. Her new psycho-neural disposition therefore never gets triggered and she continues to believe that the exit-poll predicts a Labour victory on her reliable basis.

I want to argue for two claims about Rhonda in By-Election Believer II. First: she continues to know that the exit-poll predicts a Labour victory. Second: she does not believe that Labour will win guided by the fact that the exit-poll predicts a Labour victory. Let me argue for each of these claims in turn.

First: Rhonda continues to know that the exit-poll predicts a Labour victory. To bring out why it's plausible that she does know that fact, we need to draw a clear contrast between what is going on with Rhonda at the actual world, at which her psycho-neural disposition is not triggered, and what is going on with Rhonda at the set of nearby worlds at which that disposition is triggered. At the actual world she continues to believe that the exit-poll predicts a Labour victory on the basis of her veridical and reliable memory of reading it in the local news. At the nearby worlds at which her disposition is triggered, her basis for belief has switched to a veridical but unreliable memory. Relative to her basis at the actual world, it is no accident that she arrives at the true belief that the exit-poll predicts a Labour victory. Relative to her basis at the set of nearby worlds at which the disposition is triggered, it is an accident that she holds a true belief. Therefore, she does not know that the exit-poll predicts a Labour victory at those nearby worlds. But our question is: does she know it at the actual world?

The reliability of Rhonda's actual basis gives us a reason for thinking that Rhonda knows. The only reason to doubt that she knows would be supplied by what's going on in the modally close-by circumstances just described. But the existence of closeby circumstances at which one's basis shifts to one which is unreliable, it seems to me, does not preclude one from counting as knowing at the actual world, where one persists in holding one's belief on the basis of a reliable source. Knowledge might not tolerate certain kinds of modal fragility, but it's plausible that it tolerates the sort of modal fragility exemplified by Rhonda: consistently with knowing, one might easily cease to know because one might easily change one's basis for belief. Consider, for example, much ordinary knowledge by testimony. For much knowledge by testimony, one could easily have been told by some unreliable alternative source, thus precluding one from possessing knowledge.

Next: Rhonda fails to believe that Labour will win because the exit-poll predicts so. The key to this being so lies in the truth of the following principle, which I label the Fact-Reasoning Thesis:

Fact-Reasoning Thesis Necessarily, $S$ believes that $p$ because $q$ only if $S$ has the ability to engage in an episode of conscious reasoning from the known fact that $q$ to the conclusion that $\mathrm{p}$. 
The Fact-Reasoning Thesis says that satisfying the $\left(\neg \psi_{b}\right)$ condition requires possession of the ability to engage in conscious reasoning from the knowledge one has of $\mathrm{q}$, to the conclusion that $\mathrm{p}$. An immediate clarificatory point should be made concerning the notion of ability utilised by the Fact-Reasoning Thesis. It is standard in the literature on abilities to distinguish the ability to $\phi$ here-and-now from the ability to $\phi$ in general. Compare two linguistically normal adult German speakers. Suppose that one has their mouth taped together in a cruel practical joke but the other doesn't. Then there is a sense in which both are able to speak German, but a further sense in which the victim of the joke isn't. It is this difference which is tracked by saying that both have the general ability to speak German, but only one has the ability to speak German here-and-now, or, to borrow some terminology from Maier (2015), only one has the option to speak German. The Fact-Reasoning Thesis should be read as saying that being in the state of believing that $\mathrm{p}$ because q requires having the general ability to consciously reason from the known fact that $\mathrm{q}$, to $\mathrm{p}$. Thus, the Thesis is consistent with the plausible idea that someone who satisfies the $\left(\neg \psi_{b}\right)$ condition might, because they are asleep or suffering from concussion, say, find themselves in circumstances relative to which they don't have the option to engage in the relevant act of conscious reasoning.

I want to argue that the Fact-Reasoning Thesis is true, but that in By-Election Believer II Rhonda lacks the general ability to consciously reason from the knowledge she has of the fact that the exit-poll predicts a Labour victory, to her belief that Labour will win. It follows that she does not believe guided by a fact. I offer a prima facie case in favour of each claim here: the Fact-Reasoning Thesis in Sect. 3.3.1, and the claim that Rhonda lacks the relevant general ability in Sect. 3.3.2.

\subsubsection{The fact-reasoning thesis defended}

Let us begin with the Fact-Reasoning Thesis. I first want to establish that an analogue of the Fact-Reasoning Thesis is true of the $\left(\psi_{b}\right)$ condition: that when one believes that $\mathrm{p}$ because one believes that $\mathrm{q}$, it follows that one has the general ability to consciously reason from one's belief that q, to p. I will then extend the line of reasoning to the $\left(\neg \psi_{b}\right)$ condition, thereby delivering us the truth of the Fact-Reasoning Thesis.

Believing that $\mathrm{p}$ because one believes that q requires that one can be held responsible for one's belief: that one can properly be held to account if one's belief is not as it ought to be, and credited if it is. At the intersection of contemporary epistemology and the theory of mental agency, one often finds it claimed that one can be held responsible for holding a certain mental attitude only if one has the general ability to engage in action that constitutes controlling whether one has it. That claim is prima facie plausible, defensible, and I am going to take it for granted here. ${ }^{11}$ It follows that believing that $\mathrm{p}$ because one believes that $\mathrm{q}$ requires one to have some general ability to engage in action that constitutes controlling whether one believes that p. But what could this general ability consist in, other than the general ability to engage in conscious reasoning concerning whether $\mathrm{p}$ ? This in turn gets us the result that satisfying the $\left(\psi_{b}\right)$

11 See Boyle (2009, 2011), McHugh (2010, 2012, 2013, 2014, 2017), and Hieronymi (2006, 2008, 2009) for defences of it. 
condition requires one to have the general ability to consciously reason about whether p.

Now, if one believes that $\mathrm{p}$ because one believes that $\mathrm{q}$, then presumably this has an effect on the character of the reasoning one will engage in concerning whether $p$, if one engages in such reasoning at all: one will, during the course of that reasoning, be disposed to affirm: $q$, so $p$. Adding this together with what has already been proven it follows that if one believes that $\mathrm{p}$ because one believes that $\mathrm{q}$, one has the general ability to engage in conscious reasoning about whether $\mathrm{p}$, where one is disposed, during the course of that reasoning, to infer $\mathrm{p}$ from one's belief that $\mathrm{q}$. This seems to me to simply be another way of saying that the agent can be in the $\left(\psi_{b}\right)$ condition at all only if they have the general ability to consciously reason from their belief that q, to $\mathrm{p}$.

So far, I have only managed to establish the prima facie plausibility of a claim about the $\left(\psi_{b}\right)$ condition: that it requires the general ability to consciously reason from one's belief that $\mathrm{q}$ to the conclusion that $\mathrm{p}$. The Fact-Reasoning Thesis is an analogous claim about the $\left(\neg \psi_{b}\right)$ condition: that being in the $\left(\neg \psi_{b}\right)$ condition requires the general ability to consciously reason from one's knowledge that q, to p. However, by the same line of reasoning as above we can quickly arrive at the conclusion that believing that p because q requires one to have the general ability to consciously reason about whether p. Just as believing that $\mathrm{p}$ because one believes that $q$ requires that one can be held responsible for one's belief, so that one has the capacity to control for what one believes through conscious reasoning, this holds likewise for believing that $\mathrm{p}$ because $q$.

I have said that when one believes that $p$ because one believes that $q$, one will be disposed to consciously reason from one's belief that $q$, to $\mathrm{p}$, if one engages in conscious reasoning at all. But plausibly, there is a difference between the character of the reasoning one is disposed to engage in insofar as one satisfies the $\left(\neg \psi_{b}\right)$ condition and the character of the reasoning one is disposed to engage in merely insofar as one satisfies the $\left(\psi_{b}\right)$ condition. The $\left(\neg \psi_{b}\right)$ condition constitutively involves knowledge of the fact that $q$, and it's therefore plausible that the reasoning in question will take the form of reasoning that takes one from one's knowledge of the fact that $q$, to the conclusion that $\mathrm{p}$. It follows that the $\left(\neg \psi_{b}\right)$ condition, unlike the $\left(\psi_{b}\right)$ condition, comes along with a general ability to let the fact guide one in one's conscious thinking about whether $\mathrm{p}$, and in particular a general ability to draw a conscious inference from the known fact on the basis of which one holds one's belief, to the belief in question. This is just the Fact-Reasoning Thesis.

\subsubsection{Rhonda's inability}

What, finally, about the claim that Rhonda doesn't have the general ability to consciously reason from her knowledge that the exit-poll predicts a Labour victory to her belief that Labour will win? To make a case in favour of this, we should start by noting some prima facie plausible principles concerning the modal relationship between the ascription of a general ability to $\phi$ to an agent, and their having the option to $\phi$. It will help to bring these principles out by considering a pair of cases. Consider first a stroke victim who is paralysed down their right side. We would not want to say of them that they have the option to raise their right arm: there-and-then they cannot raise it. Also, 
we would not want to ascribe to them the general ability to raise their right arm. But consider next the case of an agent who has had their right arm super-glued to their chest as part of a prank. Like the stroke victim, they do not have the option of raising their right arm. But unlike the stroke victim, they do have the general ability to do so. What grounds this difference between our two impaired agents?

Taking my lead from some suggestions made by Maier (2015), I think the key to the difference lies in a modal difference between them. The victim of the prank is such that in a sufficient range of relevant close-by possible worlds, they have the option to raise their arm. The stroke victim, by contrast, doesn't have the option to raise their arm in a sufficient range of relevant close-by worlds; necessarily: an agent has the general ability to $\phi$ only if, in a sufficient range of relevant close-by circumstances, they have the option to $\phi$. This seems to me to be a prima facie plausible starting point in explaining the difference between the two agents: although neither agent has the option to move their right arm, the stroke victim's incapacitation is in some way more modally robust than that of the victim of the practical joke.

But this is only the beginning an account. To make further progress with it, we will have to spell-out in an illuminating manner what makes a close-by circumstance relevant, when considering whether to ascribe a general ability to $\phi$. Although I cannot offer a complete account here, I do want to draw attention to one kind of circumstance which we will have to discount as relevant. Consider again our stroke victim and let us add the following details to their case: they are, in a few moments time, to undergo ground-breaking surgery which, if successful, would fully restore to them the neuro-physiological conditions which ground the ability, in our species, to engage in right-arm raisings. Since one wouldn't have to change things very much in order for them to have already undergone a successful surgery (we can suppose that easily, the operation might have successfully taken place a day before), there is a set of close-by worlds at which they have the option to raise their right arm. But it is a datum that the stroke victim does not have the general ability to raise their right arm. So we must conclude that these close-by possible worlds, at which the operation has been successfully carried out, are not relevant.

The lesson to draw here is that necessarily, an agent has the general ability to $\phi$ only if, in a suitable range of close-by circumstances where those features of their actual constitution which could plausibly be construed as controlling for whether they have the general ability to $\phi$ are held fixed, they have the option to $\phi$. For each ability, we have at least a rough-and-ready, and perhaps empirically informed, conception of those aspects of the agent's mental, neural, or bodily constitution which are explanatorily relevant to the agent's possession of the relevant general ability. We must restrict our attention, when determining whether to ascribe a general ability, to close-by worlds at which those aspects remain the same as at the actual world, and see if, at those worlds, the agent has the option to $\phi$. This is the restriction that needs to be placed on the notion of relevance operated with by the modal principle linking general abilities and options already cited.

But if this conception of the relationship between general abilities and options is correct, we have a case for thinking that Rhonda lacks the general ability to consciously reason from her knowledge that the exit-poll predicts a Labour victory to her belief that Labour will win. Relative to salient elements of Rhonda's psycho-neural constitution, 
were she to consciously address the question of who will win the by-election, she would cease to know that the exit-poll predicts a Labour victory. That means that at closeby worlds at which we hold salient elements of Rhonda's psycho-neural constitution fixed, she doesn't have the option to engage in the kind of reasoning at issue. This suffices, I have argued, for her to lack the general ability to engage in such reasoning at the actual world. In this respect, Rhonda's position is more analogous to that of the stroke victim, than that of the victim of the practical joke.

\subsection{The nature of being guided by a fact}

I now want to offer a case in favour of thinking that it can be explained why Rhonda in By-Election Believer II fails to be guided by a fact only if we reject the monitic conception of the rational-motivation relation.

Suppose we agree that there are two kinds of rational-motivation relation. The first kind is neutral on whether the agent is in either kind of good case or bad; it requires only that it appear to the agent as if $\mathrm{q}$ is a normative reason for them to believe that $\mathrm{p}$. The second is essentially successful to a certain degree; it can be instantiated at all only if the agent believes that $\mathrm{p}$ because $\mathrm{q}$, so that their belief that $\mathrm{p}$ is guided by the fact that q. And suppose we identify cases in which the $\left(\neg \psi_{b}\right)$ condition holds with cases in which the latter kind of rational-motivation relation holds. As I said in Sect. 3.1, this would be a rejection of the core idea which motivates the Composite View, which is that there is only the first sort of relation. If this is so, then we'd have a straightforward account of what's going on in By-Election Believer II: Rhonda fails to satisfy the $\left(\neg \psi_{b}\right)$ condition because instantiating the second kind of rational-motivation relation requires that she possesses the general ability to consciously reason from the known fact that $\mathrm{q}$, to $\mathrm{p}$.

Although this might be a possible explanation of why Rhonda fails to be guided by a fact I will need to show that there is no better competing explanation compatible with the core idea that motivates the Composite View. And surely, it will be suggested, there is: we should simply add to Composite-Guidance ${ }_{K}$ the following condition:

Composite-Guidance $_{K} * \mathrm{~S}$ believes that $\mathrm{p}$ because $\mathrm{q}$ iff (i) $\mathrm{S}$ believes that $\mathrm{p}$ because $\mathrm{S}$ believes that q; (ii) $\mathrm{S}$ knows that q; (iii) $\mathrm{S}$ has the general ability to consciously reason from her knowledge that $\mathrm{q}$, to p.

It will then be suggested that adding condition (iii) is entirely consistent with the core idea that (i) cannot be constituted by an essentially successful condition-that is, with accepting a monistic conception of the rational-motivation relation. If that's correct, this gets us a competing explanation of the case, compatible with the core idea that motivates the Composite View: Rhonda simply fails to be guided by a fact because she fails to satisfy condition (iii).

However, I don't think the proponent of the monistic conception of the rationalmotivation relation is in a position to offer this competing explanation. To see why, consider the following question: how must the proponent of the monistic conception think of the ability to consciously reason from one's knowledge that q, to p? Well, the proponent of the monistic conception wants to think of both of the good case conditions 
as factoring into the $\left(\psi_{b}\right)$ condition plus the relevant additional factors. Given that, I think they are committed to thinking that the ability to consciously reason from one's knowledge of $\mathrm{q}$, to $\mathrm{p}$ factors in an analogous fashion. That is, given their endorsement of the factoring account of the good cases, they are committed to saying that possessing the general ability to consciously reason from the known fact that $\mathrm{q}$, to p consists in possessing the general ability to reason from one's belief that $\mathrm{q}$, to $\mathrm{p}$, plus having knowledge that q.

Why does the monistic conception commit one to such a picture of the relevant ability? Well let's suppose that the state of believing that $\mathrm{p}$ because $\mathrm{q}$ factors in the way laid down by Composite-Guidance $K^{*}$. But now let us try to combine this picture with the thought that the general ability to consciously reason from one's knowledge that $\mathrm{q}$, to $\mathrm{p}$ does not factor in an analogous fashion: it does not factor into the general ability to consciously reason from one's belief that q, to p, plus knowledge that q. In that case, the possession of the general ability in question will have to be thought of as consisting in a sui generis state of the agent which partly composes the $\left(\neg \psi_{b}\right)$ condition. Although this position might be coherent, I do not think that it could be well-motivated. Once it has been granted that the state of possessing a capacity to reason from the fact that $\mathrm{q}$, to $\mathrm{p}$ is sui generis there would appear to be little principled motivation for ruling it out that the state of believing that $\mathrm{p}$ because $\mathrm{q}$ is as well.

So the proponent of the monistic conception looks committed to saying that possessing the general ability to consciously reason from the known fact that $q$, to $p$ consists in possessing the general ability to reason from one's belief that $q$, to $p$, plus having knowledge that $\mathrm{q}$. But since believing that $\mathrm{p}$ because one believes that $\mathrm{q}$ suffices for one to possess the general ability to reason from one's belief that q, to $\mathrm{p}$, it follows in turn that the proponent of the monistic conception is committed to

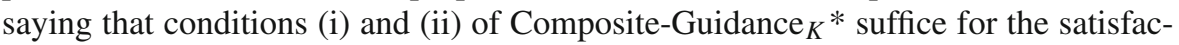
tion of condition (iii) of their account. The upshot of this is that the proponent of the monistic conception cannot, by their own lights, hope to explain why Rhonda fails to satisfy the $\left(\neg \psi_{b}\right)$ condition by appeal to the thought that Composite-Guidance ${ }_{K} *$ gives us the correct account of that condition and that she fails to satisfy condition (iii) of that account. After all, they are committed to saying that she does satisfy (iii), because they are committed to saying that she satisfies (i)-(ii) and that (i)-(ii) are jointly sufficient for (iii). So this alternative explanation isn't available to my opponent.

This completes my argument. Before moving on to look at some objections to it, however, I want to go back to something I mentioned at the end of Sect. 3.1. The argument just presented does not merely serve to render the Composite View of the $\left(\neg \psi_{b+}\right)$ unmotivated by proving false the monistic conception of the rational-motivation relation. Also, the argument provides a fresh counterexample to the Composite View, even in its strongest version. After all, By-Election Believer II serves as a counterexample to Composite View*, given that Rhonda's belief that Labour will win plausibly manifests only a disposition to reason in accordance with correct principles of reasoning. And even if Composite View* were further modified by adding, say, conditions (ii) and (iii) of Composite-Guidance $K^{*}$, which I think would amount to the strongest version of the theory, By-Election Believer II would still serve as a counterexample to it. 


\section{Objections and replies}

Let me pause to take stock. I started out in Sect. 1 with a three-way distinction between believing in the light of a normative reason, believing guided by a fact, and believing because one holds some other belief, and sketched an account of the connections between those three conditions. In Sect. 2 I went on to raise the question of how we should conceive of believing in the light of a normative reason. Following Lord and Sylvan (Forthcoming), I introduced the Composite View, a simple-minded response to that question, and I argued that Lord and Sylvan's attack on the Composite View missed the mark because it failed to undermine the general factoring idea which motivates the Composite View in the first place. According to the factoring idea, we should treat believing that $\mathrm{p}$ because one believes that $\mathrm{q}$ as our basic condition, and then conceive the two sorts of success case as factoring into that basic condition, plus additional features distinctive to each kind of success case. What followed in Sect. 3 was an attempt to undermine that general factoring idea. My strategy, outlined in Sect. 3.1, has been to demonstrate that when one believes that $\mathrm{p}$ guided by the fact that $\mathrm{q}$, the very kind of relation that holds between one's belief that $\mathrm{p}$ and the belief that q requires for its instantiation that one believes guided by the fact that q. In Sect. 3.2 I argued that acknowledging that being guided by the fact that q requires knowing that q does not in itself undermine the factoring idea. In Sect. 3.3 I then presented By-Election Believer II and argued that Rhonda, the agent in that case who believes that $\mathrm{p}$ because she believes that q, (a) knows that q, and (b) fails to count as believing that $\mathrm{p}$ because q. The argument for the latter appealed to the Reasons-Reasoning Thesis, defended in Sect. 3.3.1, in conjunction with the thought that Rhonda lacks the general ability to reason from her knowledge that q, to p, defended in Sect. 3.3.2. Finally, in Sect. 3.4 I argued that these verdicts about Rhonda suffice to fulfil my strategy for undermining the core idea which motivates the Composite View.

I now want to finish by considering three objections to the argument of Sect. 3.3. Section 4.1 considers the objection that the Fact-Reasoning Thesis over-intellectualises the $\left(\neg \psi_{b}\right)$ condition. Section 4.2 considers the objection that the Fact-Reasoning Thesis is otherwise too strong. Section 4.3 considers an objection to my claim that Rhonda lacks the relevant general ability.

\subsection{Over-intellectualisation}

One obvious worry about the Fact-Reasoning Thesis is that it seems to overintellectualise the state of believing guided by a fact; it seems that there are cases of agents who lack the general ability to reason from the facts which guide their beliefs but who nevertheless are in states of believing guided by the relevant facts. Two putative sorts of cases of this character spring to mind: cases of low-skilled cognitive agents, such as small infants and many non-human animals, and cases of implicit bias. I tackle each in turn.

Infants and Animals In response to the concern that small infants and certain types of animals can believe in the light of facts even whilst lacking conscious reasoning abilities, I want to highlight a salient feature of believing that $\mathrm{p}$ in the light of what 
appears to one to be a reason for doing so: an agent can be in such a state only if they count as having made up their mind about whether $p$. Is it plausible to think of small infants and animals as being able to make up their minds on a certain issue? To the extent that it is, I submit, it will be equally plausible to ascribe to them abilities to consciously reason. To the extent that it isn't, they can only be counted as believing guided by a fact in an attenuated sense, and not in the sense which has been my focus.

Implicit Bias Suppose that Jeremy is disposed to avow that non-native citizens should be treated equally to native citizens from the point of view of the criminal law, but that his behaviour is best interpreted as manifesting a belief that they shouldn't. This latter belief, however, is held implicitly: it does not manifest itself in any conscious judgement Jeremy is prepared to make, and Jeremy is not willing to ascribe the belief to himself, for example. It's plausible, then, that Jeremy might believe of some non-native that they are of unequal worth to natives in the eyes of the criminal law and indeed that he might do so guided by the fact that they are non-native. And yet, is it not plausible that Jeremy lacks the general ability to consciously reason from that fact, to his belief?

In response to this, I want to say that in so far as it is plausible to think of Jeremy as believing guided by a fact in the sense at issue here, the proponent of the FactReasoning Thesis will just say that part of what it is for such biases to be implicit is that the agent is rendered unable to rehearse the relevant piece of reasoning hereand-now: they do not have the option to engage in such reasoning, but nevertheless continue to have a general ability to do so. To the extent that it's implausible to ascribe Jeremy the general ability to reason in the way in question, and that will depend on further details of the case such as how modally robust the implicitness of his bias is, that will just go to show that it isn't always plausible to think of agents in such cases as believing guided by a fact in the sense of interest here.

\subsection{Sensitivity, not reasoning}

Suppose it is conceded that Rhonda does not have the general ability to reason from her knowledge about the exit-poll, to the conclusion that Labour will win. Still, it might be thought implausible that it follows from this that she doesn't believe the latter in the light of the former. That's because Rhonda plausibly continues to possess a cluster of dispositions directed towards the fact she treats as a normative reason which might seem to warrant ascription of the $\left(\neg \psi_{b}\right)$ state to her nevertheless. In particular, she continues to be disposed to automatically drop her belief when she comes to have knowledge of various facts which appear to her to be defeating conditions for her apparent evidence, such as facts which appear to her to be stronger pieces of counterveiling evidence, where to say that she is disposed to do so automatically is to say that she is disposed to do so without engaging in conscious reasoning. Her continuing to have these dispositions to automatically drop her belief in these circumstances means that Rhonda continues to be sensitive to the presence of the fact she treats as a normative reason in various ways. The objection is that all that's required for her to count as being guided by a fact is some form of sensitivity to the relevant fact, not the more demanding sensitivity-in-reasoning condition laid down by the Fact-Reasoning Thesis. 
The thing to say in response to this objection is that there are a number of further dispositions which Rhonda fails to possess. These dispositions include the disposition to weigh the fact that the exit-poll predicts a Labour victory against facts which appear to be countervailing evidence in conscious reasoning, and, as I have effectively argued already, she lacks the disposition to consciously infer that Labour will win from the fact that the exit-poll predicts a Labour victory. That's because were she to consciously raise the question of who will win, she would cease to enjoy the kind of cognitive contact with the fact that the exit-poll predicts a Labour victory which enables that fact to exert its would-be normative influence on her thinking. Presumably, if possession of the set of dispositions cited by my objector is evidence that Rhonda believes guided by a fact, by the same token it will have to be admitted that lacking the dispositions I have just cited is counter-evidence to that claim. But if that is the situation, my objector will have to demonstrate that their evidence is decisive, and I do not see how they can do that. By contrast, I have defended the claim that my own counter-evidence is decisive: that is what the argument for the Fact-Reasoning Thesis presented in Sect. 3.3.1 does.

\subsection{The individuation of general abilities}

I have the general ability to raise my right arm. I also have the general ability to raise my left arm. Is there one general ability here: the general ability to raise one's arm, which can be actualised in two different ways, or are there two general abilities: one for each arm? Suppose we opt for the former course-grained individuation of general abilities. It would follow that Rhonda does have the general ability to reason from her knowledge that the exit-poll predicts a Labour victory, to the belief that Labour will win the by-election. That's because on a coarse-grained individuation of general abilities, we'll presumably have to say that Rhonda's general ability to reason from the fact about the exit-poll to the proposition that Labour will win is identical to some yet more general ability to reason probabilistically about elections, or about political matters simpliciter, for example. But whatever more general ability we opt for, presumably Rhonda still has that ability, it's just that relative to her psycho-neural constitution she doesn't have the option of realising the ability in a way that takes the particular known-fact/proposition pair at issue as premiss and conclusion.

For present purposes I won't object to the claim that general abilities ought to be individuated in a coarse-grained manner. ${ }^{12}$ What I do want to doubt is that granting such a course-grained individuation proves problematic for my argument. To see why, let us restate the argument for the Fact-Reasoning Thesis provided in Sect. 3.3.1 in the following manner. If an agent believes that $\mathrm{p}$ because $\mathrm{q}$, they are accountable for their belief that $p$. But if an agent is accountable for their belief that $p$, they can control what they believe concerning $\mathrm{p}$. This control is exercised in conscious reasoning about whether $\mathrm{p}$. Hence if the agent believes that $\mathrm{p}$ because $\mathrm{q}$, the agent can consciously reason about whether $\mathrm{p}$. However, if the agent believes that $\mathrm{p}$ because $\mathrm{q}$ and they engage in conscious reasoning about whether $\mathrm{p}$, they are disposed to consciously infer $\mathrm{p}$ from their knowledge that $\mathrm{q}$. From this, it follows that if the agent believes that $\mathrm{p}$

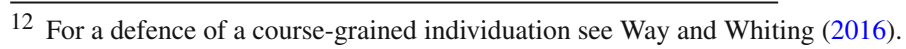


because q, they can engage in conscious reasoning from their knowledge that $\mathrm{q}$, to $\mathrm{p}$. In Sect. 3.3.1 I effectively interpreted the can here as meaning has the general ability to, which would give us the truth of the Fact-Reasoning Thesis.

Of course, we cannot interpret the can as meaning has the option to, for, as I have already mentioned, that would be far too strong. However, if we accept that general abilities are to be individuated in a coarse-grained manner, it seems to me that we should no longer interpret the can of the argument just rehearsed to mean has the general ability to either. Instead, we should go for a third option. On the third option, to say that the agent can control for what they believe, can consciously reason about whether $\mathrm{p}$, and can consciously reason from their knowledge that $\mathrm{q}$, to $\mathrm{p}$, is to say that they have the (coarsely-individuated) general ability to do those things and, they have a second-order general ability to realise the first-order ability in the specific forms in terms of which they have just been described, that is: with $q$ functioning as premiss and $\mathrm{p}$ as conclusion. Given a coarse-grained conception of general abilities, that is, we should allow a reading of can talk according to which it can be used to ascribe a conjunctive modal condition to the agent: they have the (coarsely-individuated) general ability to $\phi$ and they have the second-order general ability of realising it with the specific value of $\phi$ at issue.

This makes the following response available to the current objection. If we interpret the can which appears in the argument for the Fact-Reasoning Thesis in this third way, the argument continues to have true premisses. But those premisses now jointly entail not quite the Fact-Reasoning Thesis, but the slightly distinct claim that believing that $\mathrm{p}$ because $\mathrm{q}$ requires the possession of a (coarsely individuated) general ability to consciously reason from one's knowledge that q, to $\mathrm{p}$, and the second-order general ability to realise that first-order ability in the specific form which takes the known fact that $\mathrm{q}$ as its premiss and $\mathrm{p}$ as its conclusion. I have already effectively argued that Rhonda fails to satisfy that conjunctive modal condition in Sect. 3.3.2. Thus, this tweaked Fact-Reasoning Thesis gets me the result I want: that Rhonda does not believe guided by a fact. This, however, is a result that has now been achieved entirely consistently with acknowledging that general abilities should be individuated in a coarse-grained manner.

Open Access This article is distributed under the terms of the Creative Commons Attribution 4.0 International License (http://creativecommons.org/licenses/by/4.0/), which permits unrestricted use, distribution, and reproduction in any medium, provided you give appropriate credit to the original author(s) and the source, provide a link to the Creative Commons license, and indicate if changes were made.

\section{References}

Alvarez, M. (2010). Kinds of reasons. Oxford: Oxford University Press.

Audi, R. (1993). The structure of justification. Cambridge: Cambridge University Press.

Boyle, M. (2009). Active belief. Canadian Journal of Philosophy, 39(1), 119-147.

Boyle, M. (2011). Making up your mind and the activity of reason. Philosophers' Imprint, 11(17), 1-24.

Cunningham, J. J. (Unpublished Manuscript). “Knowledgeably responding to reasons”. https://drive.google. com/file/d/0B7if-X8oAj_vczdEU1pUQ08tQkE/view.

Hieronymi, P. (2005). The wrong kind of reason. Journal of Philosophy, 102, 437-457.

Hieronymi, P. (2006). Controlling attitudes. Pacific Philosophical Quarterly, 1(87), 45-74. 
Hieronymi, P. (2008). Responsibility for believing. Synthese, 3(161), 357-373.

Hieronymi, P. (2009). Two kinds of agency. In L. O’Brien \& M. Soteriou (Eds.), Mental actions (pp. 138-162). Oxford: Oxford University Press.

Hornsby, J. (2007a). Knowledge, belief and reasons for acting. In C. Penco, M. Beany, \& M. Vignolo (Eds.), Explaining the mental (pp. 88-105). Newcastle: Cambridge Scholars Publishing.

Hornsby, J. (2007b). Knowledge in action. In A. Leist (Ed.), Action in context (pp. 285-302). Berlin: Walter de Gruyter.

Hornsby, J. (2008). A disjunctive conception of acting for a reason. In A. Haddock \& F. Macpherson (Eds.), Disjunctivism: Perception, Action, Knowledge (pp. 262-279). Oxford: Oxford University Press.

Hyman, J. (1999). How knowledge works. Philosophical Quarterly, 50(197), 433-451.

Korcz, K. A. (2000). The causal-doxastic theory of the basing relation. Canadian Journal of Philosophy, 30(4), 525-550.

Lord, E., \& Sylvan, K. (Forthcoming). Prime time (for the basing relation). In: P. Bondy, \& J. A. Carter (Ed.), New essays on the basing relation. London: Routledge. https://www.dropbox.com/s/ 7pssnihh9458ggq/BelievingForNormativeReasons.pdf.

Maier, J. (2015). The agentive modalities. Philosophy and Phenomenological Research, 90(1), 113-134.

McHugh, C. (2010). Judging as a non-voluntary action. Philosophical Studies, 2(152), 245-269.

McHugh, C. (2012). Epistemic deontology and voluntariness. Erkenntnis, 1(77), 65-94.

McHugh, C. (2013). Epistemic responsibility and doxastic agency. Philosophical Issues, 1(23), 132-157.

McHugh, C. (2014). Exercising doxastic freedom. Philosophy and Phenomenological Research, 1(88), $1-37$.

McHugh, C. (2017). Attitudinal control. Synthese, 194(8), 2745-2762.

Parfit, D. (2001). Rationality and reasons. In D. Egonsson, J. Josefsson, B. Petersson, \& T. RonnowRasnussen (Eds.), Exploring practical philosophy (pp. 17-39). Farnham: Ashgate Aldershot.

Turri, J. (2011). Believing for a reason. Erkenntnis, 74(3), 383-397.

Way, J., \& Whiting, D. (2016). Reasons and guidance (or, surprise parties and ice cream). Analytic Philosophy, 57(2), 1-22. 